\title{
NIR reflective pigments to mitigate the urban heat islands effect (UHIE)
}

\author{
Andrea Rosati $^{*}{ }^{, 1}$, Michele Fedel $^{1}$, and Stefano Rossi $^{1}$ \\ ${ }^{1}$ Department of Industrial Engineering, University of Trento, via Sommarive n. 9, 38123 Trento, Italy
}

\begin{abstract}
For building applications, coatings are needed in order to obtain an attractive appearance and protection against the outdoor environments. Buildings are responsible for consumption of cooling energy. Cool coatings applied over buildings surface provide an effective solution for passive cooling of building indoors and influencing local outdoor microclimate, mitigating urban heat islands effect (UHIE). Cool coatings have to resistant to weathering and ageing. For this reason, we developed near infrared (NIR) reflective pigments with the aim to add in binder and obtaining a cool coating. A series of pigments displaying $\mathrm{YIn}_{0.9} \mathrm{Mn}_{0.1} \mathrm{O}_{3}-\mathrm{ZnO}$ stoichiometry was synthesized by sol-gel route. The dried gel precursor was calcined at different temperatures for $2 \mathrm{~h}\left(650^{\circ} \mathrm{C}, 800^{\circ} \mathrm{C}\right.$ and $\left.850^{\circ} \mathrm{C}\right)$ to observe the formation of a light brown pigment and two different blue shades. Precursors and calcined final pigments were characterized by using physicochemical analyses. The colour of pigments was studied using CIE-2004 $L^{*} a^{*} b^{*}$ colorimetric method. The cooling effect of pigments and their thermal stability were confirmed by NIR reflectance measurements and TGA respectively.
\end{abstract}

\section{Introduction}

The expansion of urban agglomerations is responsible of a lot of energy consumption. Buildings consume the $40 \%$ of primary energy [1]. This is because in urban environments temperatures increase for concrete and paved surfaces that adsorb solar energy. The overall effect is the overheating of urban areas respect to the rural areas. This effect is known as Urban Heat Islands Effect (UHIE). Heat islands increase the energy demand for cooling and air conditioning costs. The use of cool materials for roofs and envelopes of buildings (Figure 1.) can achieve the retention of the UHIE. This kind of materials is characterized by high solar reflectance (ability to reflect sunlight, spectrum 0.3-2.5 $\mu \mathrm{m}$ ) and high thermal emittance (ability to emit thermal radiation, spectrum 4-80 $\mu \mathrm{m}$ ) [2].

Solar radiation that reaches the surface of the earth can be divided in a 5\% of ultraviolet radiation (UV, 300$400 \mathrm{~nm}$ ), $43 \%$ of visible light (VIS, 400-700 nm) and $52 \%$ of the near infrared region (NIR, 700-2500 nm) [3]. Therefore, near infrared radiation accounts for the greater component of solar radiation. In the last decade, many efforts have been made to develop cool roofing and for walls materials, that mainly include a wide range of colourful NIR reflective pigments, to satisfy aesthetic needs and urban restrictions. Unfortunately a lot of colourful pigments are based on toxic precursors, such as cobalt [4] chromium [5], and also on synthesis routes that are time and energy consuming.

In recent times, new chemistries have been investigated focused on the development of rare earths oxides derived pigments with the following formulation: $\mathrm{Y}(\mathrm{In}, \mathrm{Mn}) \mathrm{O}_{3}$ [6]. Different shades of blue were obtained introducing $\mathrm{Mn}^{3+}$ into the trigonal bipyramidal (TBP) sites of hexagonal $\mathrm{YInO}_{3}$ [7]. This aimed to substitute and minimize the use of toxic blue pigments as cobalt aluminate $\left(\mathrm{CoAl}_{2} \mathrm{O}_{4}\right)$ and Prussian Blue $\left(\mathrm{Fe}_{4}\left[\mathrm{Fe}(\mathrm{CN})_{6}\right]_{3}\right)$ [7, 8]. As demonstrated by Li et al. [6] a "rainbow" of colours is created through various substitutions into the TBP sites of hexagonal $\mathrm{YInO}_{3}$ through sol-gel and solid state route. A further development was done by Jose et al. [9]. The NIR reflectance of $\mathrm{Y}(\mathrm{In}, \mathrm{Mn}) \mathrm{O}_{3}$ blue pigment was increased a lot by the doping with $\mathrm{ZnO}$.

In the present work a light brown pigment and two blue pigments were synthesized by a low temperature sol-gel technique, just by heating at different temperatures the dry gel with the following formula: $\mathrm{YIn}_{0.9} \mathrm{Mn}_{0.1} \mathrm{O}_{3}-\mathrm{ZnO}$. Three different pigments were achieved maintaining exactly the same formulation tuned by Jose et al. [9], acting only on the heat treatment which will give the final colour. Thermal analyses as thermogravimetry (TGA) and differential scanning calorimetry (DSC) analysis were carried out to monitor the thermal process to realize pigments. Fourier transform infrared (FT-IR) spectra of each pigment were collected to know the chemical changes at each calcination temperature. For each pigment was then obtained the ability to reflect sunlight in terms of near infrared (NIR) reflectance. The final colour was evaluated according to CIE-2004 $L * a * b *$ colorimetric method [10] with the aim to have a standard identification of each colour.

\footnotetext{
* Corresponding author: andrea.rosati@unitn.it
} 


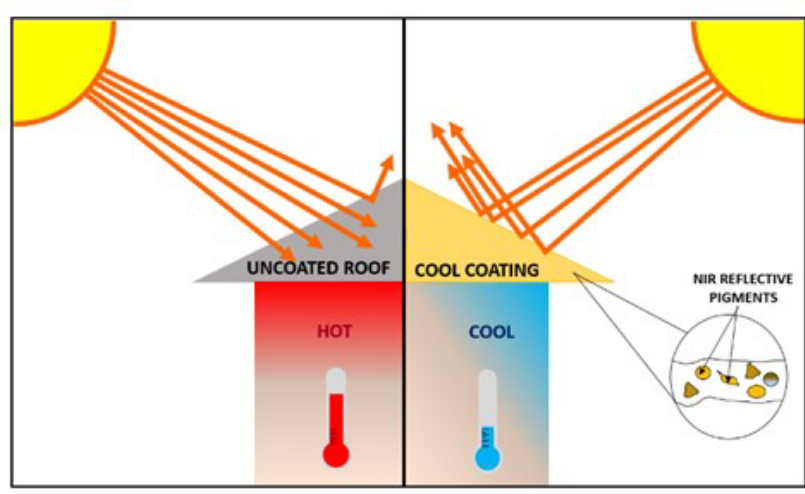

Fig. 1. Scheme that shows the basic principle of cool roof materials with NIR reflective pigments.

\section{Experimental section}

\subsection{Materials}

The chemical reagents used are $\mathrm{Y}_{2} \mathrm{O}_{3}$ (Sigma-Aldrich, 99.99\%), $\quad \mathrm{In}_{2} \mathrm{O}_{3}$ (Sigma-Aldrich 99.99\%), manganese (III) acetate (Sigma-Aldrich 97\%), ZnO <100 nm nanopowders ( $80 \%$ Zn Basis, Sigma-Aldrich) and citric acid 99\%).

\subsection{Preparation of $\mathrm{Yln}_{0.9} \mathrm{Mn}_{0.1} \mathrm{O}_{3}-\mathrm{ZnO}$ light brown and blue pigments}

The $\mathrm{YIn}_{0.9} \mathrm{Mn}_{0.1} \mathrm{O}_{3}-\mathrm{ZnO}$ pigments were synthesized by a sol-gel method. Stoichiometric amounts of yttrium oxide $(1.66 \mathrm{mmol})$, manganese (III) acetate $(0.33 \mathrm{mmol})$, indium oxide $(1.49 \mathrm{mmol})$ and zinc oxide $(3.33 \mathrm{mmol})$ were dissolved in $4.0 \mathrm{M}$ nitric acid $(100 \mathrm{~mL})$ with constant stirring at $800 \mathrm{rpm}$ and heating at $50^{\circ} \mathrm{C}$. After $1 \mathrm{~h}$, a uniform solution of reagents was obtained, and a stoichiometric amount of citric acid was added with the molar ratio of 3.5:1 respect to metal. After $6 \mathrm{~h}$ a light yellow solution was obtained. The resultant yellow solution was dried at $80^{\circ} \mathrm{C}$ to obtain a dry gel. The gel was heated at $250^{\circ} \mathrm{C}$ to decompose nitrates. The dry gel was heated at $650^{\circ} \mathrm{C}$ to obtain a light brown pigment. Part of dry gel was heated at $800^{\circ} \mathrm{C}$ and $850^{\circ} \mathrm{C}$ to obtain two different shades of blue. Each temperature of calcination was maintained for $2 \mathrm{~h}$. The calcination of the dry gel was carried out in a MAB high temperature electrical furnace by heating the samples in a ceramic crucible. The heating of the furnace was programmed to increase the temperature at $5^{\circ} \mathrm{C} / \mathrm{min}$. The FT-IR spectra of the calcined powders indicate the progressive decomposition of organic components increasing temperature of calcination.

\subsection{Characterization techniques}

A Varian 4100 FT-IR Excalibur Series instrument performed Fourier transform infrared (FT-IR) spectra of each pigment. Powders were mixed with spectroscopically pure $\mathrm{KBr}$ and pressed into tablets.
Thermogravimetry (TGA) and differential scanning calorimetry (DSC) analysis were carried out in the temperature range of $50-1000^{\circ} \mathrm{C}$ using a differential thermal analyser TG/DSC NETZSCH STA 409 PC Luxx at heating rate of $20^{\circ} \mathrm{C} / \mathrm{min}$. Thermal analyses were carried out in air atmosphere with a flow rate of 50 $\mathrm{mL} / \mathrm{min}$. TGA and DSC were carried out on the dry gel and on the blue pigment obtained through calcination of the dry gel at $850^{\circ} \mathrm{C}$.

Scanning transmission electron microscopy (S/TEM) Talos F200S, using an accelerating voltage of $200 \mathrm{kV}$, was employed to understand morphology and particle size of pigments samples (data not reported in this paper).

The optical properties of the powdered pigments were measured with a Perkin Elmer Lambda 1050 UV/VIS/NIR Spectrophotometer with an integrating sphere attachment using $\mathrm{ZnO}$ (99.0\% essay) as a reference. The $L^{*}, a^{*}, b^{*}$ colour parameters of heat treated pigments at each temperature were determined by coupling the analytical software Spectra Magic NX to the CM-2600d Spectrophotometer, following the CIE$2004 L^{*} a * b *$ colorimetric method [10] recommended by the CIE (Commission Internationale de l'Eclairage). In this method, $L^{*}$ is the lightness axis (black (0) white $(100)), a^{*}$ is the green (-) to red (+) axis, and $b^{*}$ is the blue (-) to yellow (+) axis.

\section{Results and discussions}

\subsection{Thermogravimetric and differential scanning calorimetry}

Two different thermal analyses were performed on the dry gel: a thermogravimetric analysis (TGA) and a differential scanning calorimetry (DSC). In the TGA a thermal process is represented as the change in weight of the sample versus the gradual applied rising temperature. A DSC analysis let us to know if there are material phase changes in the sample, as crystallization. Peaks and curves that describe chemical changes in the material under a thermal treatment represent the difference between the thermal flows in the substance and a reference, while both are undergoing a program temperature controlled.

Both the integral curve and the derived curve of TGA are shown in the thermogram of the citrate dry gel (Figure 2 (a).). On the integral curve it is possible to detect the onset temperature, where the curve begins to descending, which corresponds to the beginning of the weight loss. On the derived curve, the maximum rate of weight loss of the sample, shown by a downward peak, is assumed as the decomposition temperature. The slight slope between 80 and $135^{\circ} \mathrm{C}$ of the TGA curve indicates the removal of adsorbed moisture. Looking at the DTGA the peak at $250^{\circ} \mathrm{C}$ confirms the decomposition of nitrates; and the peak at $400^{\circ} \mathrm{C}$ corresponds to the citric acid decomposition $[11,12]$. The corresponding part on the integral curve shows that the decomposition of citric acid is completed at $600^{\circ} \mathrm{C}$. The exothermic peaks of DSC curve (Figure 2 (b).), at $270^{\circ} \mathrm{C}$ and $420^{\circ} \mathrm{C}$, confirm 
the decomposition process of nitrate and citrate respectively. The two adjacent exothermic peaks at $420^{\circ} \mathrm{C}$ and $450^{\circ} \mathrm{C}$ are due to the combustion of citrate [13] and crystallization of $\mathrm{YInO}_{3}$ and $\mathrm{ZnO}$. The slight increase of heat flow from $600^{\circ} \mathrm{C}$ to $850^{\circ} \mathrm{C}$ corresponds to the release of residual carbon oxides [13]. From TGA and DSC (Figure 2 (a). and Figure 2 (b).), in the range from $\sim 600 / 650^{\circ} \mathrm{C}$ to $1000^{\circ} \mathrm{C}$, there are not significant mass changes or by-product formation. Furthermore, almost all the organic part is degradated and the temperature of $650^{\circ} \mathrm{C}$ can be set as the minimum temperature to make a calcination that give a pigment without relevant organic fraction but with crystalline phases.
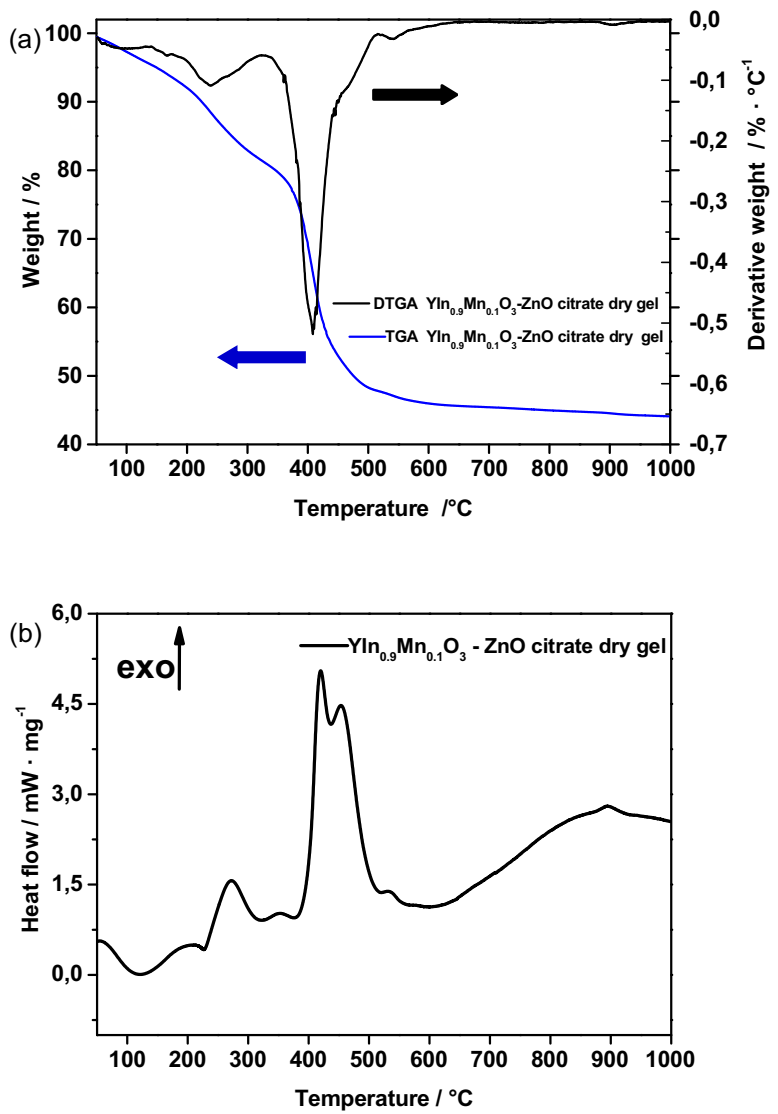

Fig. 2. TGA-DTGA (a) and DSC curve (b) of $\mathrm{YIn}_{0.9} \mathrm{Mn}_{0.1} \mathrm{O}_{3}-$ $\mathrm{ZnO}$ citrate gel.

\subsection{FT-IR}

Figure 3. shows the FT-IR spectra of the synthesized citrate gel as well as calcined powders $\left(650^{\circ} \mathrm{C}, 800^{\circ} \mathrm{C}\right.$, $850^{\circ} \mathrm{C}$ ). FT-IR analysis of each pigment allows associating each peak, produced by the absorption of infrared radiation from the material, to a chemical bond.

A lot of peaks of organic groups, in the spectrum of citrate dry gel, disappear increasing the calcination temperature. The broad band observed in the spectrum of citrate gel at $3400 \mathrm{~cm}^{-1}$ can be assigned to $\mathrm{O}-\mathrm{H}$ stretching frequencies of the intermolecular hydrogen bonded water $[12,14]$. The absorption peak at $2355 \mathrm{~cm}^{-1}$ is due to the absorption of $\mathrm{CO}_{2}$ from atmosphere [15].
Peak at $1080 \mathrm{~cm}^{-1}$ is due to $\mathrm{C}-\mathrm{O}$ stretching of the organic chain [16]. Further, the FT-IR spectrum of the citrate dry gel evidence intense absorption bands characteristic of the carboxylate groups at 1380 and 1560 $\mathrm{cm}^{-1}$ [14], which are assigned to the symmetric and asymmetric vibrations of the bond of carbonilic group of citric acid. The bands at $1400 \mathrm{~cm}^{-1}$ and $803 \mathrm{~cm}^{-1}$ are due nitrate ions vibrations [14]. The spectrum of pigment calcined at $850^{\circ} \mathrm{C}$ shows the adsorption bands of indiumoxygen bond (603 and $488 \mathrm{~cm}^{-1}$ ) [17]. Comparing all the FT-IR spectra is observed a decrease of the organic component increasing the temperature of calcination.

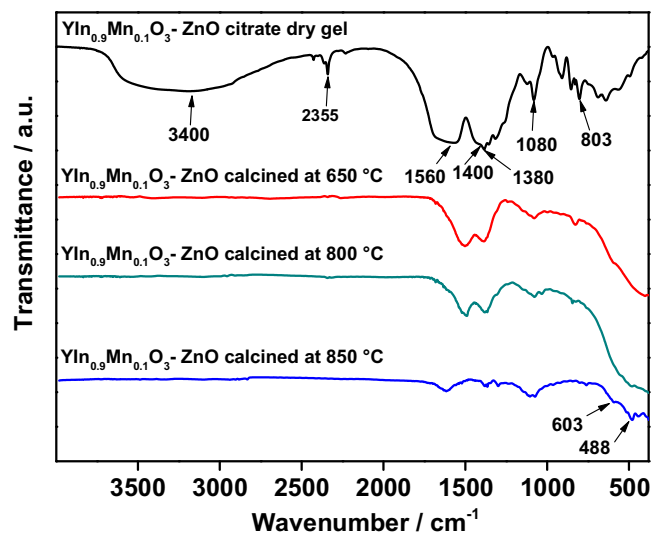

Fig. 3. FT-IR spectra of $\mathrm{YIn}_{0.9} \mathrm{Mn}_{0.1} \mathrm{O}_{3}-\mathrm{ZnO}$ citrate dry gel and pigments obtained at the three calcination temperatures $\left(650,800\right.$ and $\left.850{ }^{\circ} \mathrm{C}\right)$.

\subsection{Near infrared reflectance and thermal stability}

Considering that the large amount of total solar radiation is made by near infrared (NIR) radiation, reflection of the NIR radiation (NIR 700-2500 nm) is a good parameter to evaluate if a pigment is suitable for cool coating applications.

The near infrared (NIR) reflectance of each pigment is shown in Figure 4. Increasing calcination temperature of pigments from $650^{\circ} \mathrm{C}$, to the two higher values, there is a relevant increase in the NIR reflectance. The high value of NIR reflectance of each pigment is due to the presence of $\mathrm{ZnO}$, having high IR reflectance [18]. The small increase in the NIR reflectance of pigment calcined at $800^{\circ} \mathrm{C}$, respect to the others, shows that a decrease in temperature of calcination of $50^{\circ} \mathrm{C}$ not affects the efficiency in terms of NIR reflectance. According to this measurement, any pigment is capable to reflect sunlight and to create a cool surface. However, the robustness of NIR reflectance data must be verified because $\mathrm{ZnO}$ used as reference is not the same used in the synthesis of pigments. The latter is in form of nanopowders $(<100 \mathrm{~nm}$ particle size $)$. A further confirmation of this class of pigments as a potential employment for cool roof application is given by the thermogram of $\mathrm{YIn}_{0.9} \mathrm{Mn}_{0.1} \mathrm{O}_{3}-\mathrm{ZnO}$ pigment, calcined at $850^{\circ} \mathrm{C}$. The thermogram is obtained by TGA in air 
atmosphere and in a temperature range of $50-1000^{\circ} \mathrm{C}$ (Figure 5.). The result is a flat curve demonstrating the negligible weight loss of pigment up to $1000^{\circ} \mathrm{C}$.

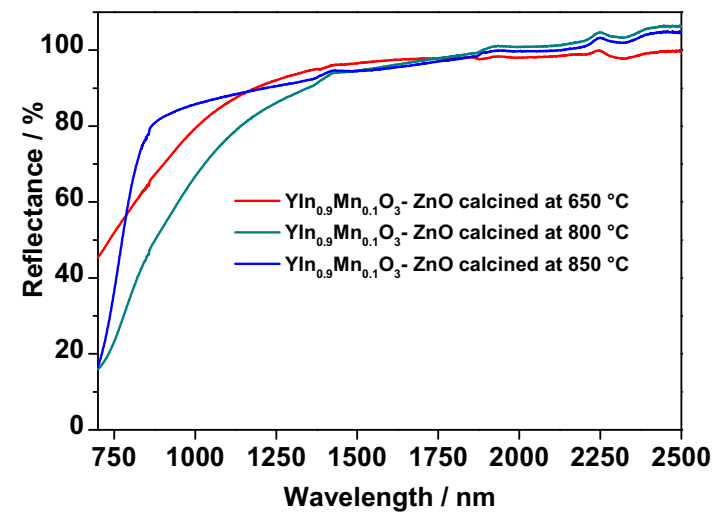

Fig. 4. NIR reflectance of the three pigment powders.

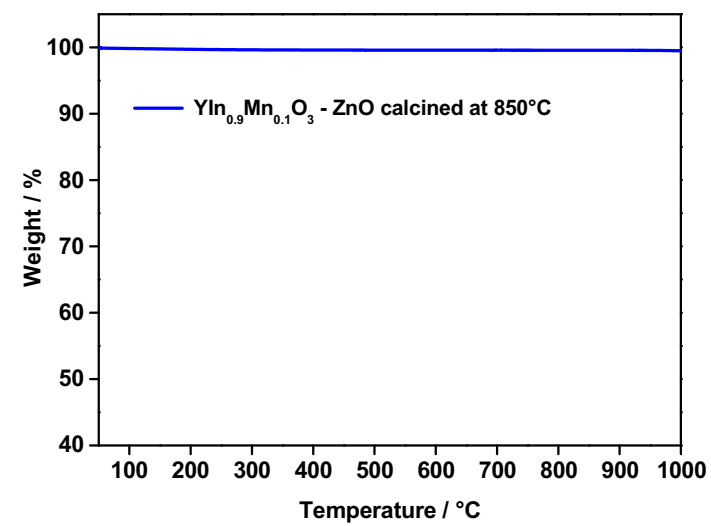

Fig. 5. Thermogram of $\mathrm{YIn}_{0.9} \mathrm{Mn}_{0.1} \mathrm{O}_{3}-\mathrm{ZnO}$ pigment calcined at $850^{\circ} \mathrm{C}$.

\subsection{Colour properties}

Considering the use of these pigments in the urban construction, identification of colours trough a standard method is a useful tool to guarantee the best reproducibility of the colours, than the visual appearance. In this work any colour is represented according to CIE-2004 $L * a * b *$ colorimetric method [10].

In Table 1. colorimetric measurements data are showed. The highest value of $L *$ is obtained for pigment calcined at $650^{\circ} \mathrm{C}$, that is a light brown (Figure 6 (a).). It's interesting to note that colour coordinates of the light brown are so near to colour coordinates of traditional tiles and brick made with clays [19, 20]. Therefore, this pigment could have a relative wide use in surfaces also for urban environments with existing buildings as well as historical ones.

The other two colours are two shades of blue: a cyan blue (Figure 6 (b).) and a deep blue (Figure 6 (c).), so we can observe a lower value of $L^{*}$.
Table 1. Colour coordinates of the three $\mathrm{YIn}_{0.9} \mathrm{Mnn}_{0.1} \mathrm{O}_{3}-\mathrm{ZnO}$ pigment powders.

\begin{tabular}{|c|c|c|c|}
\hline $\begin{array}{c}\mathrm{YIn}_{0.9} \mathrm{Mnn}_{0.1} \mathrm{O}_{3} \\
-\mathrm{ZnO}\end{array}$ & \multicolumn{3}{|c|}{ Colour coordinates } \\
\hline & $L^{*}$ & $a^{*}$ & $b^{*}$ \\
\hline $\begin{array}{c}\text { Calcined at } \\
650^{\circ} \mathrm{C}\end{array}$ & 53.48 & 11.18 & 16.58 \\
\hline $\begin{array}{c}\text { Calcined at } \\
800^{\circ} \mathrm{C}\end{array}$ & 42.08 & -6.12 & -22.88 \\
\hline $\begin{array}{c}\text { Calcined at } \\
850^{\circ} \mathrm{C}\end{array}$ & 49.64 & -5.18 & -32.75 \\
\hline
\end{tabular}
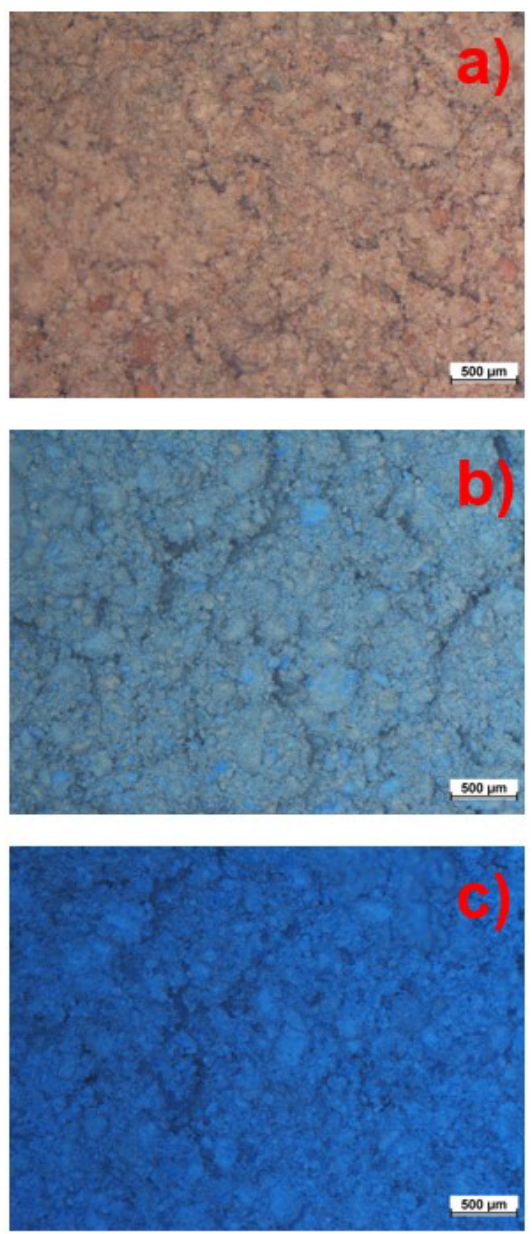

Fig. 6. $\mathrm{YIn}_{0.9} \mathrm{Mn}_{0.1} \mathrm{O}_{3}-\mathrm{ZnO}$ pigments obtained at the three calcination temperatures: 650 (a), 800 (b) and 850 (c) ${ }^{\circ} \mathrm{C}$.

\section{Conclusions}

Three different pigments were realized by sol-gel combustion method at very low temperatures and times, confirming the use sol-gel route is a low-cost method in terms of energy and times. Furthermore, three different colours were obtained without chemical modification, which doping.

All the pigments show high NIR reflectance, that rises increasing calcination temperature. Increasing calcination temperature particles become more spherical and smaller as confirmed by S/TEM images. 
Pigments calcined at $650^{\circ} \mathrm{C}$ and $800^{\circ} \mathrm{C}$ show a small amount of organic component, so we cannot test thermal stability by TGA.

Considering the colours, all these pigments are good candidates to realize cool coatings considering an application for traditional and historic urban centres (in the case of light brown) and in the perspective of the realization of colourful cool materials, as glazes or envelopes, for new buildings.

The authors are grateful to the group of Dr. Marcello Picollo [IFAC (Istituto di Fisica Apllicata Nello Carrara)], Sesto Fiorentino (Florence, Italy), for the support during the near infrared reflectance measurements.

\section{References}

1. A. Hawas, A. Al-Habaibeh, B. Medjdoub, Innovative design of an educational physical simulation tool for investigating energy consumption in buildings for enhancing public engagement, Energy Procedia. 105, 2615 (2017)

2. Q. Gao, X. Wu, Y. Fan, Q. Meng, Color performance and near infrared reflectance property of novel yellow pigment based on $\mathrm{Fe}_{2} \mathrm{TiO}_{5}$ nanorods decorated mica composites, Dye. Pigm. 146, 37 (2017)

3. T. Kolås, A. Røyset, M. Grandcolas, M. ten Cate, A. Lacau, Cool coatings with high near infrared transmittance for coil coated aluminium, Sol. Energy Mater. Sol. Cells. 196, 94 (2019)

4. W. Liu, T. Du, Q. Ru, S. Zuo, X. Yang, C. Yao, Y. Kong, Facile synthesis and characterization of 2D kaolin/ $\mathrm{CoAl}_{2} \mathrm{O}_{4}$ : A novel inorganic pigment with high near-infrared reflectance for thermal insulation, Appl. Clay Sci. 153, 239 (2018)

5. S. T. Liang, H.L Zhang, M.T. Luo, H.X. Liu, Y.L, Bai, H.B. Xu, Y. Zhang, Preparation of $\mathrm{Cr}_{2} \mathrm{O}_{3}$-based pigments with high NIR reflectance via thermal decomposition of $\mathrm{CrOOH}$, Trans. Nonferrous Met. Soc. China. 25, 2646 (2015)

6. J. Li, M. A. Subramanian, Inorganic pigments with transition metal chromophores at trigonal bipyramidal coordination: $\mathrm{Y}(\mathrm{In}, \mathrm{Mn}) \mathrm{O}_{3}$ blues and beyond, J. Solid State Chem. 272, 9 (2019)

7. A. E. Smith, H. Mizoguchi, K. Delaney, N. A. Spaldin, A. W. Sleight, M. A. Subramanian, $\mathrm{Mn}^{3+}$ in Trigonal Bipyramidal Coordination: A New Blue Chromophore, J. Am. Chem. Soc. 131, 17084 (2009)

8. Y. F. Gomes, J. Li, K.F. Silva, A.A.G. Santiago, M.R.D. Bomio, C.A. Paskocimas, M.A. Subramanian, F.V. Motta, Synthesis and characterization of $\mathrm{Y}(\mathrm{In}, \mathrm{Mn}) \mathrm{O}_{3}$ blue pigment using the complex polymerization method (CPM), Ceram. Int. 44, 11932 (2018)

9. S. Jose, A. Jayaprakash, S. Laha, S. Natarajan, K. G. Nishanth, M. L. P. Reddy, Y $\mathrm{In}_{0 .} \mathrm{Mn}_{0.1} \mathrm{O}_{3}-\mathrm{ZnO}$ nano-pigment exhibiting intense blue color with impressive solar reflectance, Dye. Pigm. 124, 120
(2016)

10. I. Commission, CIE 15: Technical Report: Colorimetry, 3rd edition, 552, (2004)

11. P. N. M. Dos Anjos, E. C. Pereira, Y. G. Gobato, Study of the structure and optical properties of rareearth-doped aluminate particles prepared by an amorphous citrate sol-gel process, J. Alloys Compd. 391, 277 (2005)

12. S. Vivekanandhan, M. Venkateswarlu, N. Satyanarayana, Synthesis and characterization of nanocrystalline $\mathrm{LiNi}_{0.5} \mathrm{Co} 0.5 \mathrm{VO}_{4}$ powders by citric acid assisted sol-gel combustion process, J. Alloys Compd. 462, 328 (2008)

13. S. Yu, W. Jing, M. Tang, T. Xu, W. Yin, B. Kang, Fabrication of Nd:YAG transparent ceramics using powders synthesized by citrate sol-gel method, J. Alloys Compd. 772, 751 (2019)

14. G. V. Rama Rao, D. S. Surya Narayana, U. V. Varadaraju, G. V. N. Rao, S. Venkadesan, Synthesis of $\mathrm{YBa}_{2} \mathrm{Cu}_{3} \mathrm{O}_{7}$ through different gel routes, J. Alloys Compd. 217, 200 (1995)

15. S. Senthilkumaar, K. Rajendran, S. Banerjee, T. K. Chini, V. Sengodan, Influence of Mn doping on the microstructure and optical property of $\mathrm{ZnO}$, Mater. Sci. Semicond. Process. 11, 6 (2008)

16. J. F. Q. Rey, T. S. Plivelic, R. A. Rocha, S. K. Tadokoro, I. Torriani, E. N. S. Muccillo, Synthesis of $\mathrm{In}_{2} \mathrm{O}_{3}$ nanoparticles by thermal decomposition of a citrate gel precursor, J. Nanoparticle Res. 7, 203 (2005)

17. M. Blosi, S. Albonetti, M. Dondi, A. Costa, M. Ardit, G. Cruciani, Sol-gel combustion synthesis of chromium doped yttrium aluminum perovskites, J. Sol-Gel Sci. Technol. 50, 449 (2009)

18. N. Kiomarsipour, R. S. Razavi, Hydrothermal synthesis of $\mathrm{ZnO}$ nanopigments with high UV absorption and vis/NIR reflectance, Ceram. Int. 40, 11261 (2014)

19. A. De Bonis, G. Cultrone, C. Grifa, A. Langella, A. P. Leone, M. Mercurio V. Morra, Different shades of red: The complexity of mineralogical and physico-chemical factors influencing the colour of ceramics, Ceram. Int. 43, 8065 (2017)

20. L. M. Schabbach, D. L. Marinoski, S. Güths, A. M. Bernardin, M. C. Fredel, Pigmented glazed ceramic roof tiles in Brazil: Thermal and optical properties related to solar reflectance index, Sol. Energy. 159, 113 (2018) 